University of Nebraska - Lincoln

DigitalCommons@University of Nebraska - Lincoln

2012

\title{
A notched coupon approach for tensile testing of braided composites
}

\author{
Lee W. Kohlman \\ The University of Akron, lee.w.kohlman@nasa.gov \\ Justin L. Bail \\ Ohio Aerospace Institute \\ Gary D. Roberts \\ NASA Glenn Research Center \\ Jonathan A. Salem \\ NASA Glenn Research Center \\ Richard E. Martin \\ Cleveland State University \\ See next page for additional authors
}

Follow this and additional works at: https://digitalcommons.unl.edu/nasapub

Part of the Physical Sciences and Mathematics Commons

Kohlman, Lee W.; Bail, Justin L.; Roberts, Gary D.; Salem, Jonathan A.; Martin, Richard E.; and Binienda, Wieslaw K., "A notched coupon approach for tensile testing of braided composites" (2012). NASA Publications. 65.

https://digitalcommons.unl.edu/nasapub/65

This Article is brought to you for free and open access by the National Aeronautics and Space Administration at DigitalCommons@University of Nebraska - Lincoln. It has been accepted for inclusion in NASA Publications by an authorized administrator of DigitalCommons@University of Nebraska - Lincoln. 


\section{Authors}

Lee W. Kohlman, Justin L. Bail, Gary D. Roberts, Jonathan A. Salem, Richard E. Martin, and Wieslaw K. Binienda 


\title{
A notched coupon approach for tensile testing of braided composites
}

\author{
Lee W. Kohlman ${ }^{\mathrm{a}, \mathrm{c}, *}$, Justin L. Bail ${ }^{\mathrm{b}}$, Gary D. Roberts ${ }^{\mathrm{c}}$, Jonathan A. Salem ${ }^{\mathrm{c}}$, Richard E. Martin ${ }^{\mathrm{d}}$, \\ Wieslaw K. Binienda ${ }^{\text {a }}$
}

${ }^{a}$ The University of Akron, Akron, $\mathrm{OH}$, United States

${ }^{\mathrm{b}}$ Ohio Aerospace Institute, Cleveland, $\mathrm{OH}$, United States

${ }^{\mathrm{c}}$ NASA Glenn Research Center, Cleveland, $\mathrm{OH}$, United States

${ }^{\mathrm{d}}$ Cleveland State University, Cleveland, $\mathrm{OH}$, United States

\section{A R T I C L E I N F O}

\section{Article history:}

Received 20 June 2011

Received in revised form 27 September 2011

Accepted 16 December 2011

Available online $\mathrm{xxxx}$

\section{Keywords:}

A. Fabrics/textiles

A. Polymer-matrix composites

B. Strength

D. Mechanical testing

\begin{abstract}
A B S T R A C T
A notched coupon geometry was evaluated as a method for tensile testing of 2D triaxial braid composites. Edge initiated shear failure has been observed in transverse tension tests using straight-sided coupons based on ASTM D3039. The notched coupon was designed to reduce the effects of edge initiated failure and produce the desired tensile failure. A limited set of tests were performed with partial pressurization of tubes to determine the transverse tensile strength in the absence of edge initiated failure. The transverse strength measured with the notched coupons was considerably higher than the straight-sided coupons, comparable to the tube results, and closer to the maximum possible strength based on maximum fiber strain. Further investigations of the effects of the observed biaxial stress state and stress concentrations in the notched geometry are needed.
\end{abstract}

Published by Elsevier Ltd.

\section{Introduction}

Uniaxial tensile properties of materials are used directly as one measure of material performance and as part of the material property input required for analysis of complex structures. In principle, the uniaxial test method used to obtain a reliable tensile strength value is simple to perform. A specimen with large length to width ratio is loaded along its axis until failure occurs. However, there are many issues that can affect the reliability of the measured value. Homogeneous, isotropic materials are the simplest to test. For these materials, surface flaws resulting from specimen preparation can have a large effect on measured strength. In addition, the specimen geometry must be properly designed to ensure failure within the gage region of the specimen rather than in the transition from the gage region to the gripped ends of the specimen. Alignment of the specimen in the test rig is also important, especially for brittle materials. There is also a possibility of a dependence of the measured value on specimen size because of the statistical nature of failure initiation at local defect sites.

Testing of unidirectional, continuous fiber composite materials presents additional challenges because these materials are strong along the fiber direction but weak transverse to the fiber direction. Tabs are generally recommended for testing unidirectional material in the fiber direction to avoid failure due to stresses induced at the

* Corresponding author at: NASA Glenn Research Center, Cleveland, OH, United States. Tel.: +1 2164335568 .

E-mail address: lee.w.kohlman@nasa.gov (L.W. Kohlman). grips, but failure initiation can occur as a result of peel stresses at the ends of these tabs [1]. Use of a "dogbone" specimen in which the width transitions from a larger value at the grips to a smaller value in the gage region is often not a useful approach because the shear strength of the unidirectional laminate is too small to allow sufficient load transfer from the thinner to the wider section. In addition, exposed free fiber ends in the transition region can become sites for premature failure initiation. Also, it is difficult to measure useful transverse tensile strength with a unidirectional straightsided coupon because, in real applications, the transverse strength of a lamina is increased by the suppression of notch sensitivity by adjacent plies; loads can bypass transverse cracks through fibers in adjacent plies [2].

Measurements on angle-ply and cross-ply laminates are easier to perform because the tensile strength is lower than that of a unidirectional composite and because there is higher strength in the direction transverse to the load direction. Test standards, including ASTM D3039 [1], have been developed to measure the tensile strength of such laminates. Also, methods have been developed to calculate the tensile strength of a unidirectional laminate (i.e. a lamina) from tensile tests performed on cross-ply laminates [2]. This approach overcomes the limitations described above for directly testing tensile strength using unidirectional specimens. However, this method is subject to the assumptions imposed by the use of classical lamination plate theory (CLPT) which includes the requirement that the lamina be in a state of plane stress [3] which is not necessarily true in all laminations. An additional consideration with 
this approach is that the lamina strength (in the fiber direction) calculated in this way represents the strength of a $0^{\circ}$ ply (or plies) surrounded by a $90^{\circ}$ ply (or plies) rather than the strength that would be measured directly using a unidirectional laminate. The strength in the fiber direction calculated from tests on cross-ply laminates could therefore be lower than the true lamina strength if the adjacent plies induce a premature failure by processes such as transverse cracking. This is not necessarily a disadvantage if the goal is to measure a strength value that is representative of the composite material as it is used in a laminated structure. Another important concern for angle-ply and cross-ply laminates is the possibility of premature failure resulting from interlaminar stresses at specimen free edges [4].

The test methods described above and the methods for calculating lamina properties from laminated composites have additional limitations for use with textile-reinforced composites, including fabrics and braids. One major limitation is a result of the locally varying (in plane) properties of fabrics and braids since methods for calculating lamina properties rely on the assumption of homogeneous strain and stress distributions in a uniaxial specimen. The use of high resolution digital image correlation (DIC) during a tensile test reveals local and global strain field distortions due to the development of local, architecture dependent load paths and damage. This damage can be expected to cause redistribution of internal loads, resulting in an inhomogeneous stress state.

This paper addresses the need to develop new test methods for measuring reliable tensile strength values for braided composites. Previous work has identified formation of edge damage and local splitting of fiber tows as processes that can have a large effect on tensile strength measured using standard straight-sided specimens [5-9]. Ivanov et al. [10] provides additional information on damage processes in triaxial braid composites under tensile load. While local splitting of fiber tows is a characteristic of the material that could cause a true reduction in tensile strength, premature failure caused by edge damage is a deficiency of the test method. An alternate "bowtie" specimen geometry which mitigates the possibility of edge initiated failure has been considered [11]. Measurements made using bowtie specimens have yielded higher tensile strength values compared to those measured using straight-sided specimens. However, disadvantages of the bowtie specimen are the complexity of specimen fabrication and the non-uniform state of stress and strain in the gage region. Edge damage was also not completely eliminated with these specimens. In this paper, an alternate "notched" specimen geometry is evaluated. This specimen is much simpler to fabricate than the bowtie specimen, but still has the disadvantage of having a non-uniform state of stress and strain in the gage region. In order to measure tensile strength under a more uniform state of stress and strain that better approximates a uniaxial load condition, a test method using partial internal pressurization of braided composite tubes was developed. In addition to having a more uniform state of stress and strain in the gage region, edge initiated failure is eliminated because failure initiation in the tube specimen occurs in a region of the tube away from free edges. Full-field surface strains were measured in order to determine the strain field induced in the notched and tube specimens. An evaluation of the notched and tube test geometries based on these fullfield strain measurements is presented in this paper. Preliminary results are presented comparing the tensile strengths measured using straight-sided, notched, and tube specimens.

\section{Materials}

\subsection{Fiber and matrix materials}

Composite panels were fabricated by resin transfer molding (RTM) using two-dimensional triaxial braided preforms and $177^{\circ} \mathrm{C}\left(350^{\circ} \mathrm{F}\right)$ cure epoxy resins. A high strength, standard modulus carbon fiber, TORAYCA T700S (Toray Carbon Fibers America, Inc.), was used for all panels. Several matrix materials were used. Most of the test method development was done using EPIKOTE Resin 862/EPIKURE Curing Agent W matrix (Resolution Performance Products, now Hexion Specialty Chemicals). This matrix material is a readily available two-part system that is easy to process because of its low viscosity and long working life at room temperature. This resin system will be called E862 in this report. Two other matrix materials were used to examine the effects of matrix toughness. CYCOM PR 520 matrix (Cytec Industries, Inc.) is a onepart toughened resin specifically designed for the RTM process. Hexcel's 3502 epoxy is a one-part brittle matrix material that is not typically used as an RTM resin but has flow and cure properties that are suitable for RTM processing.

\subsection{Braided preform}

A braid architecture with a $\left[+60^{\circ} / 0^{\circ} /-60^{\circ}\right]$ layup containing $24 \mathrm{k}$ tows in the $0^{\circ}$ (axial) direction and $12 \mathrm{k}$ tows in the $\pm 60^{\circ}$ (bias) directions was examined. Although larger fiber bundles were used in the axial direction, the fiber bundle spacing in the axial and bias directions were adjusted to give the same fiber volume in the axial and bias directions. This is a quasi-isotropic architecture so the global in-plane stiffness properties are expected to be the same in all directions when the region of interest includes a sufficient number of unit cells.

\subsection{Resin transfer molding}

Composite panels were fabricated by placing six layers of the $\left[+60^{\circ} / 0^{\circ} /-60^{\circ}\right]$ braided preform into the RTM mold with the $0^{\circ}$ fibers aligned in the same direction. Although the axial $\left(0^{\circ}\right)$ fibers in the various layers were aligned, the lateral position of the axial tows in the six layers was random. Resin was injected into the closed mold and cured according to processing conditions recommended by the resin manufacturer. The E862 and PR 520 materials were cured for $2 \frac{1}{2} \mathrm{~h}$ at $177^{\circ} \mathrm{C}\left(350^{\circ} \mathrm{F}\right)$ and the 3502 was cured for $2 \mathrm{~h}$ at $177^{\circ} \mathrm{C}\left(350^{\circ} \mathrm{F}\right)$. Cured panel dimensions (after trimming) were $0.6096 \mathrm{~m}(2 \mathrm{ft})$ wide by $0.6096 \mathrm{~m}(2 \mathrm{ft})$ long by $3.175 \mathrm{~mm}$ ( 0.125 in.) thick. The $56 \%$ target for fiber volume was confirmed by measurements using the acid digestion technique.

The braided composite tubes were manufactured by over braiding six layers of triaxial braid on a mandrel, followed by RTM. Test results are presented here for tubes made with E862 resin and T700S fiber. The fiber volume fraction, braid angles, tow selections, and cure conditions were chosen to match, as closely as possible, the parameters of the flat panel material. The preforming methods and molding procedures were adjusted as successive tubes were fabricated in order to reduce defects and optimize the process. As a result, some of the tubes had known defects (mainly local distortion of fiber tows) prior to testing.

\section{Experimental methods}

\subsection{Mechanical test methods}

Tensile testing was performed on an axial/torsion test machine capable of loading to $222 \mathrm{kN}$ (50,000 lbs). All flat coupon tests were conducted under displacement control at a rate of $1.27 \mathrm{~mm} / \mathrm{min}$ (0.05 in./min) in accordance with ASTM D3039 Section 11.3.2 for constant head-speed tests [1].

Two flat coupon geometries were used for tensile testing. These included a straight-sided coupon based on ASTM D3039 and a double edge notch coupon shown in Fig. 1. The ends of the 


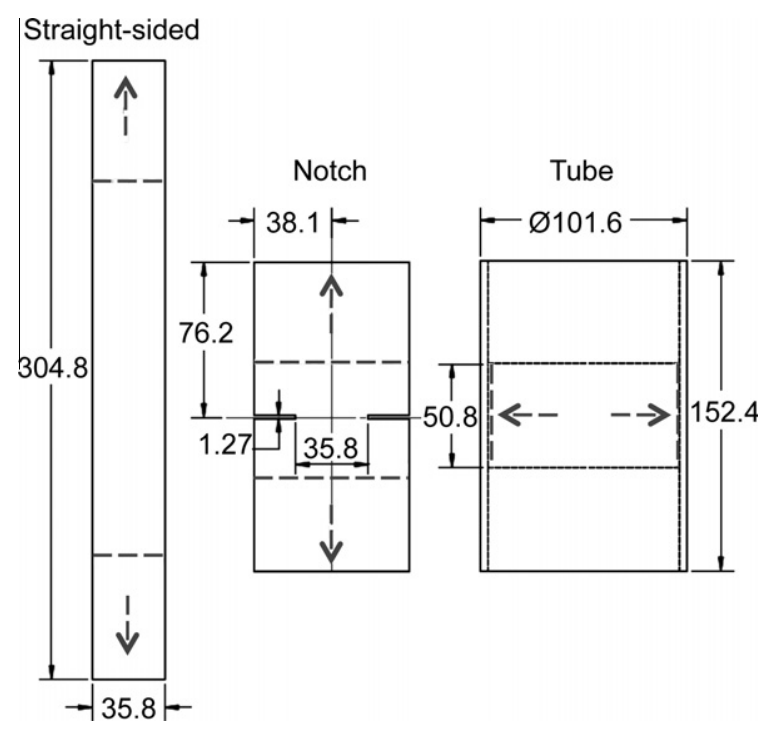

Fig. 1. Straight-sided, notch, and tube specimen geometries with loading indicated.

straight-sided coupon are clamped by hydraulic grips, resulting in an unsupported section $20.3 \mathrm{~cm}$ ( 8 in.) between the grips. The straight-sided coupons were machined using a low feed rate diamond saw. The notched specimens were first cut using abrasive waterjet machining, after which, the notches were cut using a low feed rate diamond saw. Approximately $5.1 \mathrm{~cm} \mathrm{(2} \mathrm{in.)} \mathrm{on} \mathrm{each} \mathrm{end}$ of the notch coupons were within the hydraulic grips. The dimensions (in $\mathrm{mm}$ ), grip area, and load direction of both flat coupons are shown in Fig. 1. Both geometries could be used for both axial and transverse orientations without modification. The axial direction is defined as the direction parallel to the $0^{\circ}$ fiber tow, while transverse is perpendicular to the $0^{\circ}$ tow. Fig. 2 shows the triaxial braid architecture and indicates the axial and transverse directions with respect to the material braid directions. The transverse straight-sided coupon includes no tows that extend from grip to grip. In this case, the edge initiated damage discussed above releases the fiber tow at the edge of the specimen and allows damage to propagate along the now unconstrained fiber tow. The axial straight-sided and both axial and transverse notched coupons have some tows that are gripped at both ends. This allows the load to be carried beyond the stress that induces edge damage because, in order for the specimen to fail, fibers must fail in tension. Average strain, local strain, damage accumulation, and the uniformity of the global strain field are examined using DIC methods described below.

Partial internal pressurization of braided tubes was performed using a rubber insert. The dimensions and pressurization region of the tube specimen are shown in Fig. 1. The insert extends axially approximately $1 / 3$ of the length of the tube (centered on the

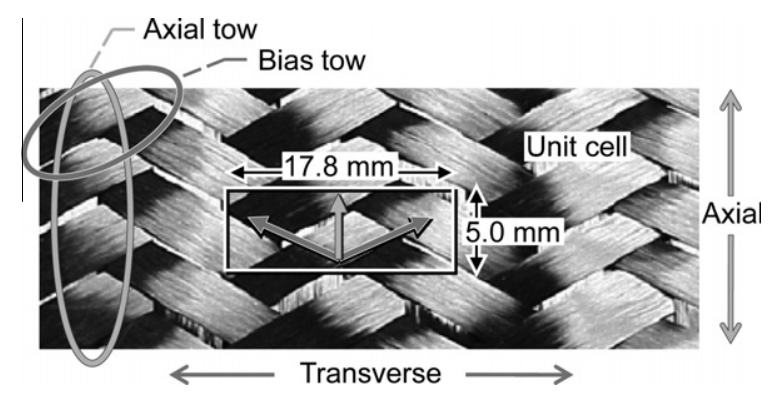

Fig. 2. Triaxial braid architecture, axial and transverse orientations are identified.

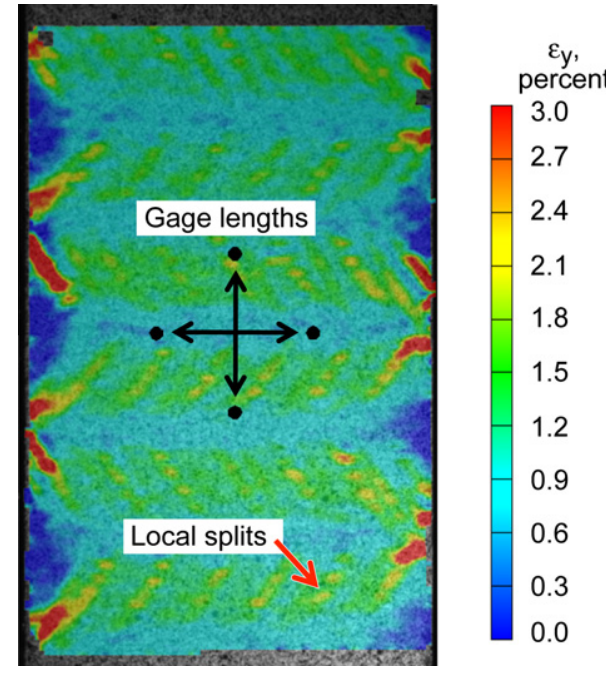

Fig. 3. Optical strain gage $(12.7 \mathrm{~mm})$ location on a specimen and surface cracks. (For interpretation of the references to colour in this figure legend, the reader is referred to the web version of this article.)

length) which was also approximately equal to the tube radius $(\sim 5 \mathrm{~cm})$. The tube wall thickness, approximately $3.175 \mathrm{~mm}$ ( 0.125 in.), is sufficient to use thin wall tube approximations. When the rubber insert is loaded in compression, it results in a hoop load in the center $1 / 3$ of the tube. The goal of this method is to induce a hoop stress with very low axial stress to simulate a transverse, uniaxial load condition. Finite element models were
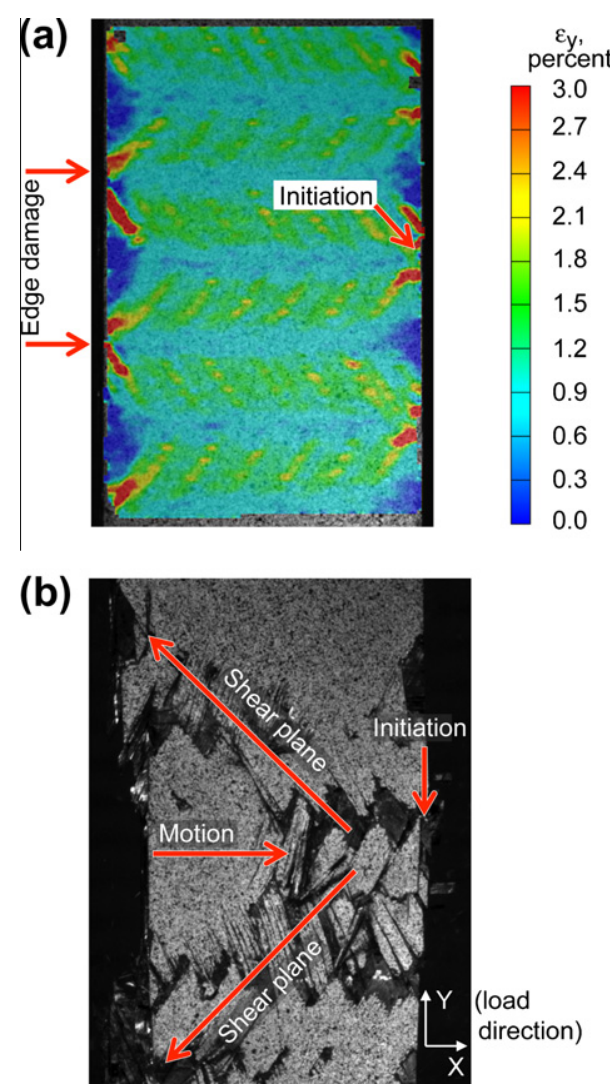

Fig. 4. (a) Edge damage identified in a transverse specimen using DIC. (b) A shear failure. (For interpretation of the references to colour in this figure legend, the reader is referred to the web version of this article.) 
used to determine that there is a maximum tensile load in the axial direction which is approximately $1 / 4$ of the applied hoop load [12]. This method also has the advantage that failure does not initiate near a free edge or geometric stress concentration, but rather at a point near the center of the coupon. One possible problem is sensitivity to defects caused by the more complex manufacturing process required for tubes compared to that used for flat plates.

\subsection{Digital image correlation methodology}

DIC was chosen instead of conventional strain gages because it eliminated the need to physically attach a sensor to the surface of the specimen and it can provide full field strain and displacement measurement. Also, strains measured by strain gages have been shown to be dependent on gage size because of local architecture [8]. Displacements in all three coordinate directions are measured with the DIC system ( $\mathrm{x}$-specimen transverse, $\mathrm{y}$-specimen longitudinal, and z-specimen out of plane) allowing the calculation of fullfield strain. The DIC software calculates surface strains in the $x$ and $y$ coordinate directions. It can also provide information on local surface damage. This is discussed in more detail by Littell et al. [7].

The DIC measurement system used was commercially available and consisted of two stereo digital cameras connected to a computer with simultaneous image capture and DIC software. During testing, a calibration process was first performed to calculate and store the relative camera position and orientation. The calibrated measurement area for the cameras was approximately $35 \mathrm{~mm} \times 28 \mathrm{~mm} \times 28 \mathrm{~mm}$, with a maximum displacement resolution of approximately $10^{-3} \mathrm{~mm}$. The corresponding load for each set of images was recorded by an analog input from the axial/torsion machine. This was used to calculate the instantaneous specimen stress (load divided by initial minimum specimen cross section) and generate stress-strain curves.

Approximately 150-350 pictures were taken by the camera system, on average, during tensile loading. Two software variables were kept constant for all testing. These included the size of the tracked pixel groups and the offset from one pixel group to the next. The DIC method tracks the locations of the pixel groups in real 3D space. The software then compares the changing surface locations during loading with the baseline locations on an unloaded specimen (immediately before the test) and calculates relative and absolute displacements and strains. The pixel group size was kept constant at $13 \times 13$ pixels and an offset of 9 pixels was used.

Once the strains were calculated, various visual representations were generated by the software using color variation to represent strain, displacement, and other computed values on the specimen surface. In order to generate stress-strain data, an optical strain extensometer was created by exporting displacement data at selected points followed by performing $\Delta L / L$ calculations (change in
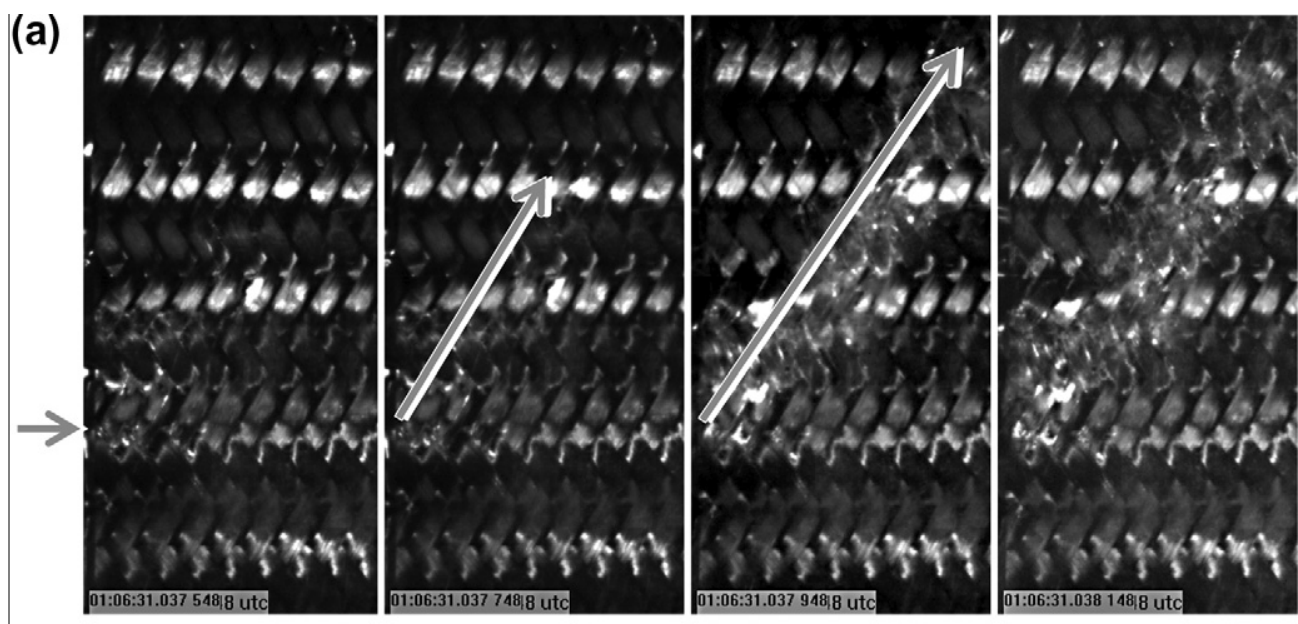

(b)

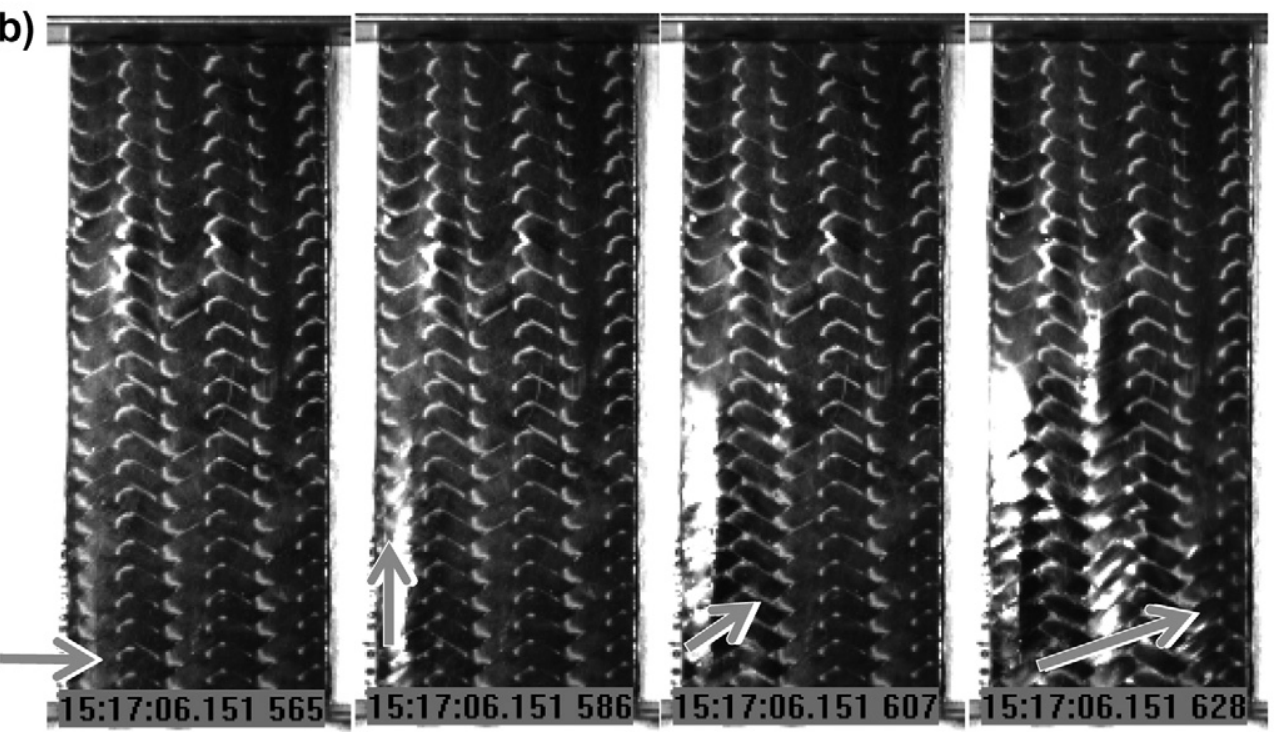

Fig. 5. High speed video capture of tensile failure. (a) Transverse. (b) Axial. 
length divided by original length). A $12.7 \mathrm{~mm} \times 12.7 \mathrm{~mm}$ $(0.5$ in. $\times 0.5$ in.) optical strain extensometer was used to measure an average strain over an area. This was intended to mimic a similarly sized strain gage. Gliesche showed that such a comparison could be done between an extensometer and DIC [13]. Limited testing was performed with strain gages, but these suffered from premature failure of the strain gage due to local surface splitting breaking the conduction path of the gage. The optical extensometer was used to account for the non-uniform strain field which results from the specimen architecture and local damage (opening of local surface cracks causes DIC to measure artificially high local strain). An example of an optical extensometer is shown if Fig. 3. Crack opening is clearly visible as high locally measured strains, examples of which are also indicated in Fig. 3.

\subsection{X-ray computed tomography}

Prior to testing, composite tube samples were inspected using microfocus X-ray computed tomography (CT). Utilizing a cone beam microfocus $\mathrm{X}$-ray source and an area detector, the technique was able to generate full field, three dimensional images of the samples. Data was analyzed using various image processing tech-
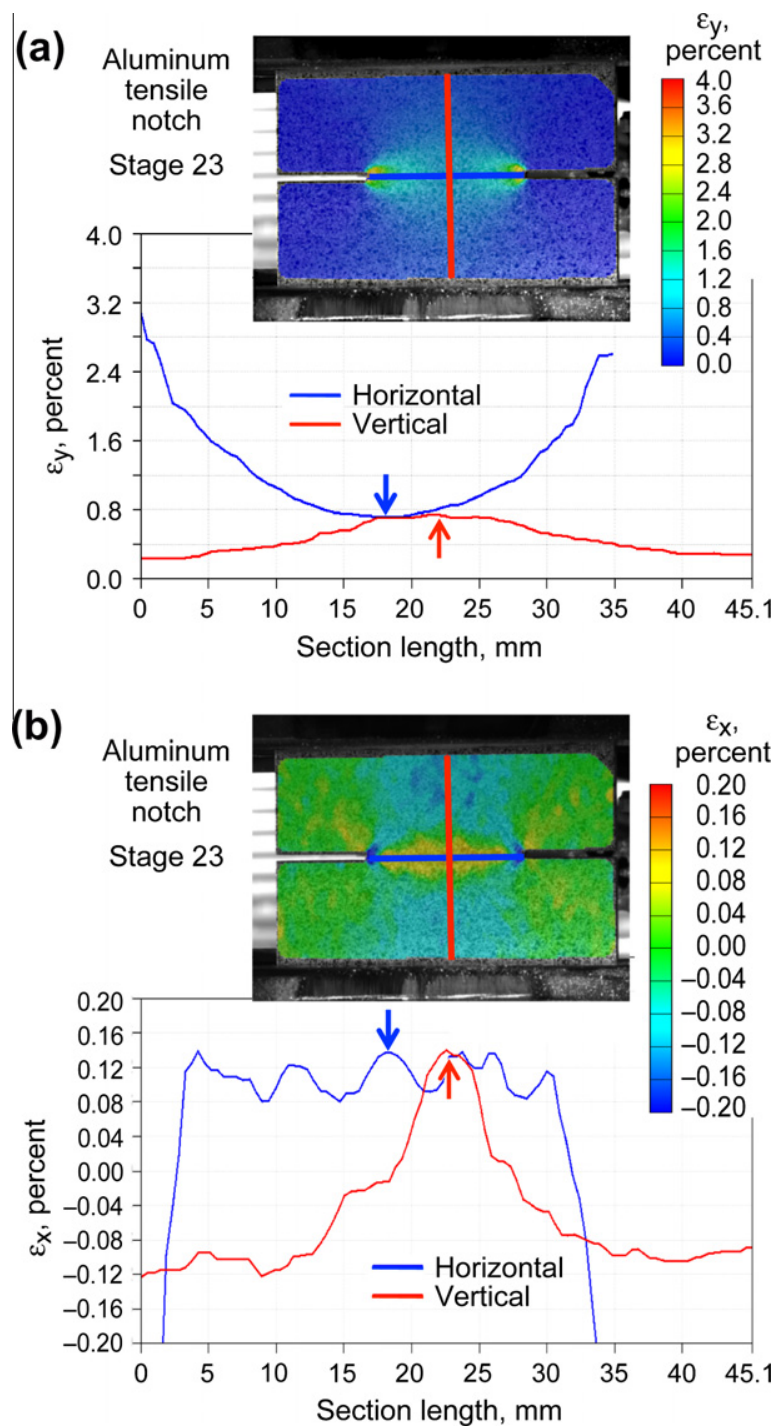

Fig. 6. Strain distribution in a notched aluminum specimen, center indicated by arrows. (a) Vertical strain, parallel to load. (b) Perpendicular strain. (For interpretation of the references to colour in this figure legend, the reader is referred to the web version of this article.) niques to generate radial $\mathrm{CT}$ slices through the thickness of the samples. This data was then examined for processing defects such as fiber misalignment and resin rich regions.

\subsection{Acoustic emission}

During one of the partial internal pressurization tests, a set of four acoustic emission transducers were mounted to the sample at $90^{\circ}$ intervals on the outer surface of the tube. Acoustic emission events were recorded continuously during specimen loading and a post test analysis of the data was performed. Using arrival times of the acoustic signals, event locations were calculated and plotted. Data was used to identify the location of damage as loading progressed and to verify damage/failure was not initiated outside of the gage section of the specimen.

\section{Experimental results and discussion}

\subsection{Straight-sided coupon tests}

The results of tensile tests performed using straight-sided coupons have been reported previously [5-9]. This previous work identified edge damage as a probable cause for low transverse tensile strength measurements and a possible cause for slightly reduced axial strength measurements. Fig. 4 shows edge damage in a transverse tension triaxial braid coupon before failure and the resulting shear type failure observed after the test. The failure shown in Fig. 4 is one of two failure modes observed in straight-sided transverse tension tests. In this example, the failure initiates as damage on the right edge and propagates as shear failure along both bias fiber directions. The other commonly observed failure propagates as a shear failure along only one bias fiber direction. Edge initiation and shear propagation of failure has been confirmed with high speed video obtained using Phantom v7.3 cameras. Fig. 5a shows the edge initiated failure of a transverse tension specimen with a single bias direction shear failure. Fig. 5b shows the failure of an axial tension specimen which is also observed to start at an edge, toward the bottom left for this test, followed by propagation across the specimen. The initiation of failure at a free edge introduces test sensitivity to machining induced defects and the internal stresses inherently associated with fiber tow termination and free edge boundary

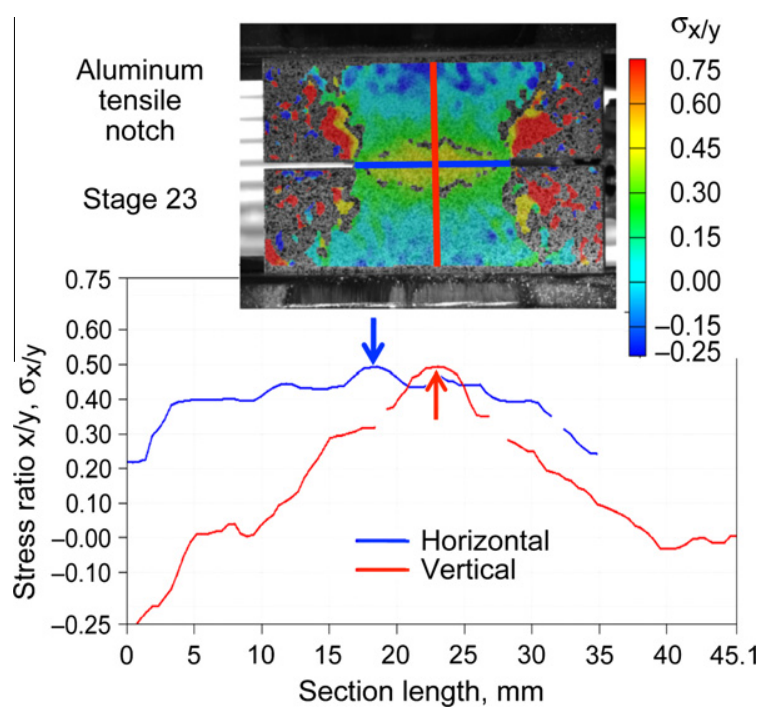

Fig. 7. Local relative perpendicular in-plane stress component, centers of section lines indicated by arrows. (For interpretation of the references to colour in this figure legend, the reader is referred to the web version of this article.) 
conditions discussed earlier [4], ultimately leading to a reduction in measured strength. Further investigation of the reduction of measured axial strength due to edge initiation is required.

\subsection{Notched tensile tests - aluminum}

The notched tensile coupon is designed to suppress the edge initiated failures shown in Figs. 4 and 5a. A consequence of the specimen design is a non-uniform gage region. In order to examine the global non-uniform strain field in the absence of the local non-uniformity induced by the composite architecture, tests were performed with a homogeneous, isotropic material (aluminum 6061). All data presented for this test was obtained at a load level before yielding occurred and therefore, the response is linear elastic. Strain parallel to load (vertical direction, $\varepsilon_{y y}$ ) is shown along section lines for a notched aluminum specimen in Fig. 6a and strain perpendicular to load (horizontal direction, $\varepsilon_{\mathrm{xx}}$ ) is shown in Fig. $6 \mathrm{~b}$. The multiaxial load state resulting from the coupon geometry was estimated using Hooke's Law (Eqs. (1) and (2)), Poisson ratio $v=0.33$, full field surface strains $\left(\varepsilon_{\mathrm{xx}}\right.$ and $\left.\varepsilon_{\mathrm{yy}}\right)$, and the assumption of a plane stress state (Eq. (3)) [14].

(a)
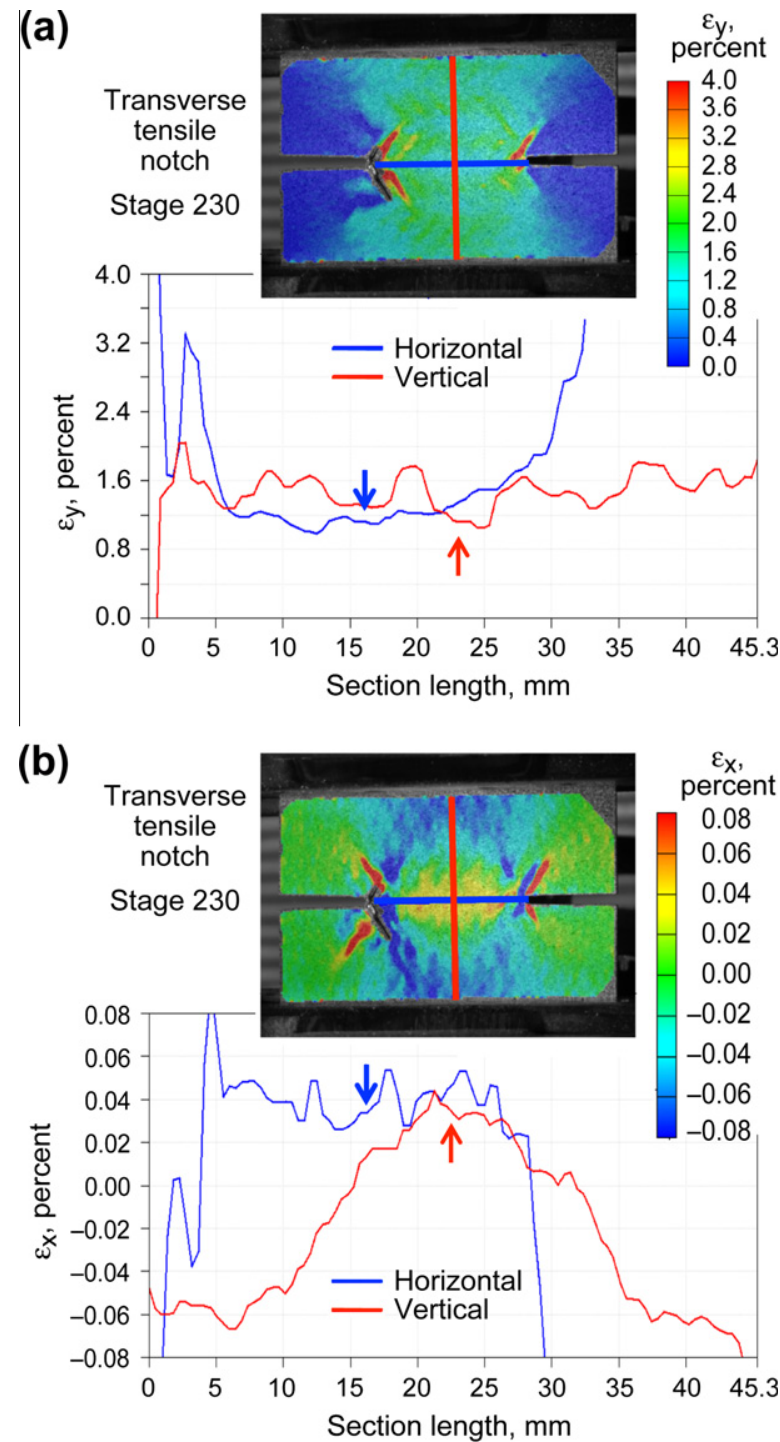

Fig. 8. Strain distribution in a notched composite specimen, center indicated by arrows. (a) Vertical strain, parallel to load. (b) Vertical strain, perpendicular to load. (For interpretation of the references to colour in this figure legend, the reader is referred to the web version of this article.)

$$
\sigma_{\mathrm{xx}}=\frac{E}{((1+v)(1-2 v))}(1-v) \varepsilon_{\mathrm{xx}}+v\left(\varepsilon_{\mathrm{yy}}+\varepsilon_{\mathrm{zz}}\right)
$$

$$
\sigma_{\mathrm{yy}}=\frac{E}{((1+v)(1-2 v))}(1-v) \varepsilon_{\mathrm{yy}}+v\left(\varepsilon_{\mathrm{xx}}+\varepsilon_{\mathrm{zz}}\right)
$$

$\varepsilon_{\mathrm{zz}}=\frac{v}{(1-v)}\left(\varepsilon_{\mathrm{xx}}+\varepsilon_{\mathrm{yy}}\right)$

The relative stress state (the relative magnitude of perpendicular stress, $\sigma_{\mathrm{xx}}$, with respect to parallel stress, $\sigma_{\mathrm{yy}}$ ) was calculated using Eq. (4). The result is not dependent on the modulus $(E)$.

$\frac{\sigma_{\mathrm{xx}}}{\sigma_{\mathrm{yy}}}=\frac{(1-v) \varepsilon_{\mathrm{xx}}+v\left(\varepsilon_{\mathrm{yy}}+\varepsilon_{\mathrm{zz}}\right)}{(1-v) \varepsilon_{\mathrm{yy}}+v\left(\varepsilon_{\mathrm{xx}}+\varepsilon_{\mathrm{zz}}\right)}$

The accuracy of this solution depends on the accuracy of the measured surface strains. At low strain levels, the error is high because the signal to noise level is low. To account for this, all results calculated from strains below a minimum threshold were removed. The remaining data was used to generate Fig. 7, which indicates that the gage region is under biaxial tension. The missing data surrounding the center of the specimen is a result of the perpendicular strain $\left(\varepsilon_{\mathrm{xx}}\right)$ crossing zero. The perpendicular stress component $\left(\sigma_{\mathrm{xx}}\right)$ ranges from approximately $0.5 \sigma_{\mathrm{yy}}$ at the center to $0.2 \sigma_{\mathrm{yy}}$ near the notch tip. It should be noted that this method was included to provide insight into the possible stress state of the composite notch specimen before damage occurs. The accumulation of damage causes the quasi-isotropic stiffness assumption to no longer be valid. In addition, the Poisson ratio for the composite is not $v=0.33$.

\subsection{Notched tensile tests - composite}

Strain parallel to load (vertical direction) is shown along section lines for a notched composite specimen in Fig. 8a and strain perpendicular to load is shown in Fig. 8b. The specimen (PR 520) is highly loaded (776 MPa) and near failure. Unlike the straight-sided transverse specimen in Fig. 4, the strain pattern in the notched composite is not significantly affected by the presence of free edges and only limited damage is present around the notch location. Similar to straight-sided specimens, local strain variations are caused by damage in the local architecture and appear as local maxima in the section line plots.

Fig. 9 shows the strengths for the three composite materials that were tested in the axial and transverse directions as both

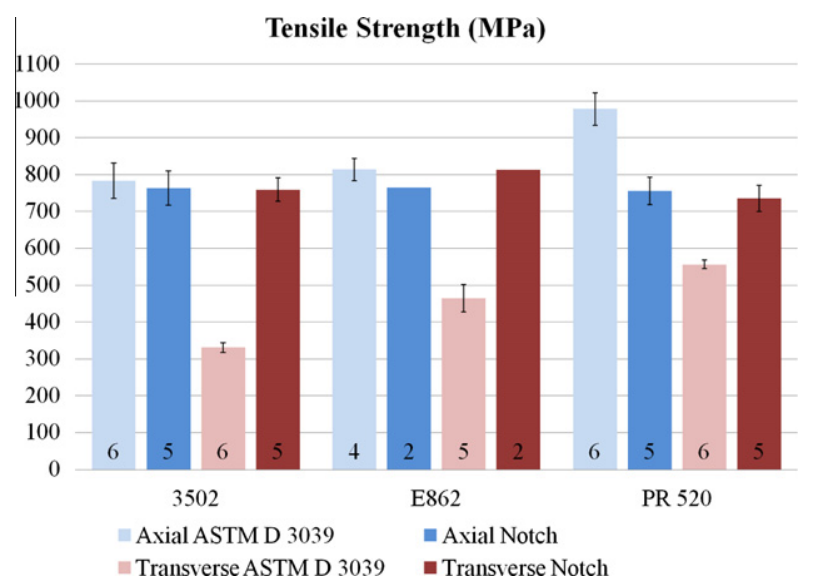

Fig. 9. Strengths of notch and straight-sided specimens versus matrix material. (For interpretation of the references to colour in this figure legend, the reader is referred to the web version of this article.) 
straight-sided and notch geometries. Testing of the straight-sided and notched composite specimens in the transverse direction produced higher strength values for the notch geometry, approaching double the straight-sided strength in the case of the brittle 3502 based composite. Fig. 9 is the average of all tests performed at each condition. The error bars represent one standard deviation and the number of specimens is denoted in the bottom of each bar. The strengths of the transverse straight-sided specimens (Fig. 9, red squares) increase with toughness due to the resistance of the matrix to propagating edge initiated damage. The transverse notch specimen (Fig. 9, dark red) constrains the edge damage to a localized area around the notch and forces a tensile failure (Fig. 10, E862) instead of a shear failure (Fig. 4, E862). This results in significantly higher measured strengths which are closer to the axial strengths. The measured transverse notch strengths are likely still low because of the stress concentration in the area of the notch. The stress concentration of the notch specimen has a greater effect on composites with tougher matrices and results in a loss of strength for the toughened material (PR 520 composite) in the axial direction (Fig. 9, dark blue). This implies that even though the notch produces a higher transverse strength value than the straight-sided coupon, it is still a lower bound on the actual material strength. The strength of the brittle system (3502) in the axial direction appears to be unaffected when comparing notch and straight-sided specimens (Fig. 9, blue) but this too may be misleading. High speed videos taken of specimen failure in axial coupons also suggest an edge initiation (Fig. 5b), which again could be expected to be more severe in the more brittle matrix composites and could mean that axial straight-sided measurements for 3502 and E862 may also be low. The real strengths of the materials should be due to local damage accumulation such as the splitting discussed earlier and not a result of tow termination at free edges or other geometric effects.

In order to determine the effects of the biaxial stress state on the failure strength of the composite notch specimen, more needs to be known about the failure surface. A more complex failure surface for 2D triaxial braids has been suggested by Swanson and Smith $[15,16]$, though considerable scatter is present in the data.

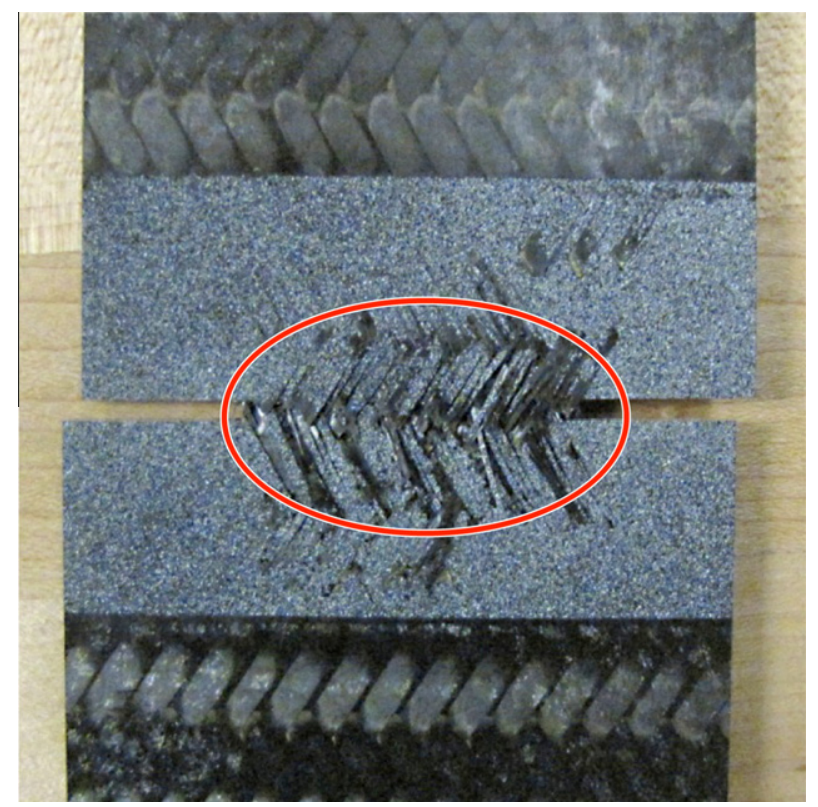

Fig. 10. Tensile failure of a composite transverse tension specimen. (For interpretation of the references to colour in this figure legend, the reader is referred to the web version of this article.)
It is expected that there will be some interaction between the $x$ and $y$ components, but this data is difficult to measure and not currently available for the materials discussed in this paper. Research is currently underway to attempt to accurately measure the failure surface for this material while excluding the effects of free edges using tension/torsion/pressurization of tubes. This should provide additional data against which to evaluate the notched geometry.
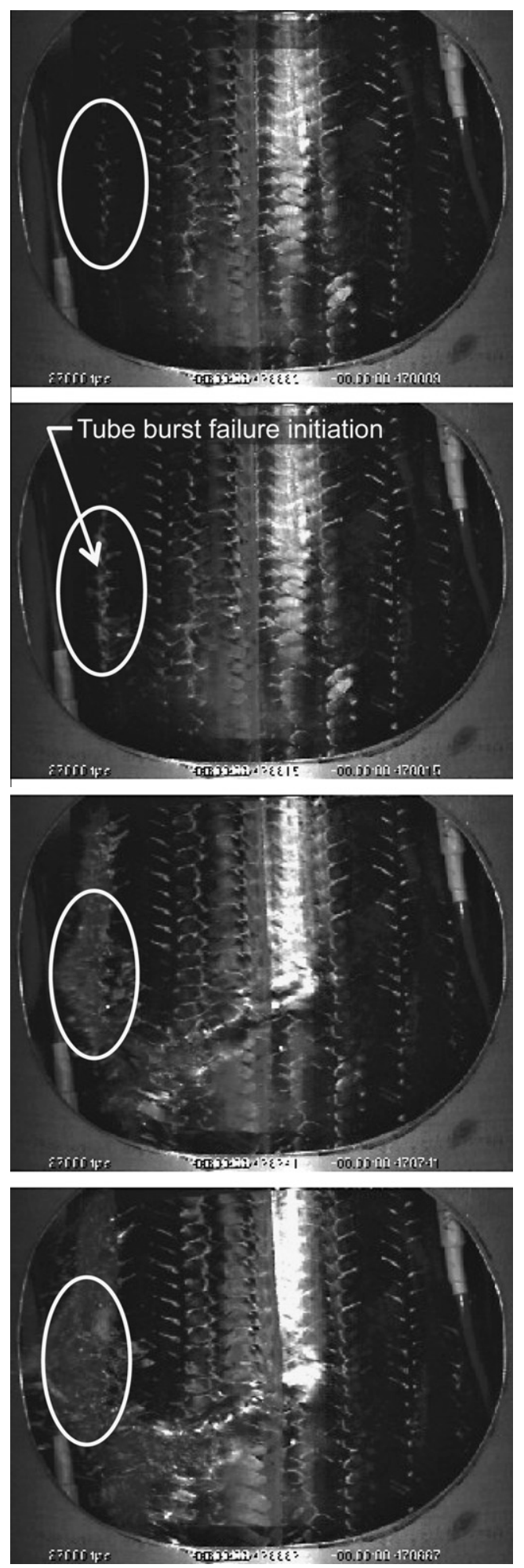

Fig. 11. High speed video capture of tube burst failure initiation. 

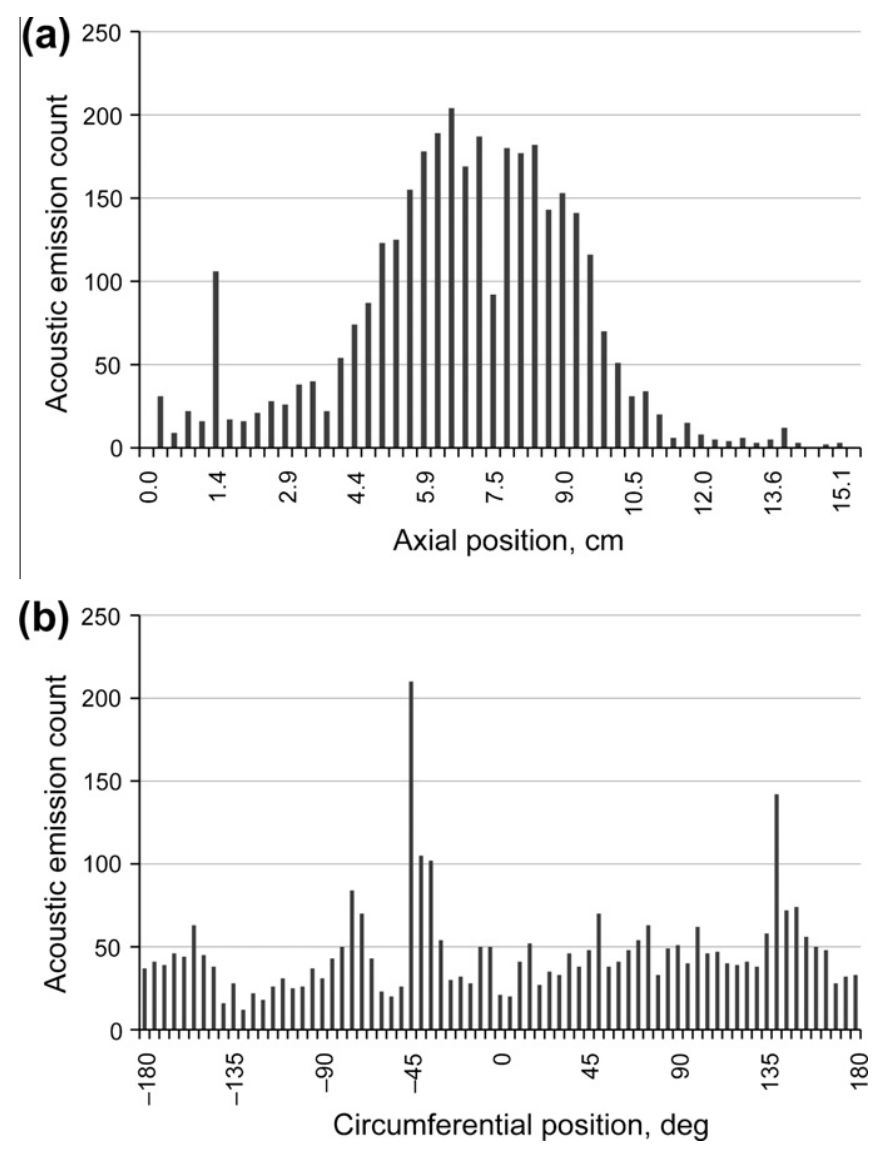

Fig. 12. Axial and circumferential locations of acoustic emission events during a tube pressurization test. (a) Axial distribution of acoustic events. (b) Circumferential distribution of acoustic events.

\subsection{Partial internal pressurization of tubes}

Fig. 11 is a series of images from a high speed video that captured the burst failure of an E862 tube specimen (transverse tensile failure). This failure initiates at the center of the tube where maximum stress occurs, as expected. The stress-strain response for the tubes is nearly linear until stresses are comparable to the straightsided strength in the axial direction. Ultimate strains are $\sim 1.8 \%$ which is near that of the fiber $(\sim 2.1 \%)$ and the straight-sided axial tension tests. Additionally, acoustic emission techniques were used to identify the locations of damage accumulation. The axial (a) and circumferential (b) locations of acoustic events are shown in Fig. 12. Axially, the majority of acoustic events are located in the center $1 / 3$ of the tube which corresponds with the $1 / 3$ loading area. Circumferentially, events tend to be concentrated at the mold lines. X-ray CT was also used to detect tube defects such as braid misalignment and distortion. A radial cross section of the tube

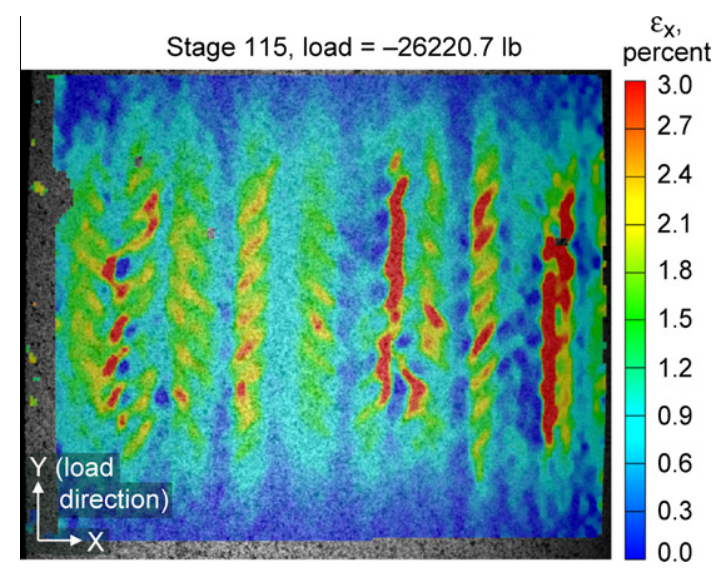

Fig. 14. Local strain variations in a pressurized tube, similar to straight-sided and notched specimens. (For interpretation of the references to colour in this figure legend, the reader is referred to the web version of this article.)

was generated as a flat image in order to identify circumferential locations of these defects. This was used to identify the location on the tube to be viewed with DIC or high speed video in order to capture failure. An example of a circumferential tube cross section showing braid distortion is shown in Fig. 13.

The tubes exhibit substantial local strain variation similar to straight-sided specimens; this is shown in Fig. 14. Again, this variation is also due to local damage creating artificially high strain measurements where cracks occur. Several methods have been investigated to deal with this local variation. These methods include optical extensometers, section line averaging, and radial measurement with cylinder fitting. An example of $\Delta R / R$ (radial strain measurement using the change in radius divided by original radius) obtained using the cylindrical method is shown in Fig. 15. This method uses a cylindrical coordinate system to measure changes of the entire specimen to reduce the effects of local damage on the measured hoop (transverse) strain. Substantially more investigation of the strain state is needed to better understand the material behavior. Additional details on the test and analysis methods for partial internal pressurization will be provided by Salem et al. [12].

Tube burst strengths for E862 composite are compared to straight-sided and notched tensile strength in Table 1. Partial pressurization of tubes and notched tensile specimen results show comparable transverse strength estimates compared to axial tensile strength. This confirms that the transverse straight-sided specimen strengths are low compared to the strength in a structure and it is in agreement with the values measured by the notch specimens. The strength measured by the notch and current tube specimens may still be low, however, because of the stress concentrations in the notched coupons and the presence of defects in the current tube specimens. Improvements to the manufacturing method for the tubes, with the goal of reducing or eliminating such defects, are ongoing.

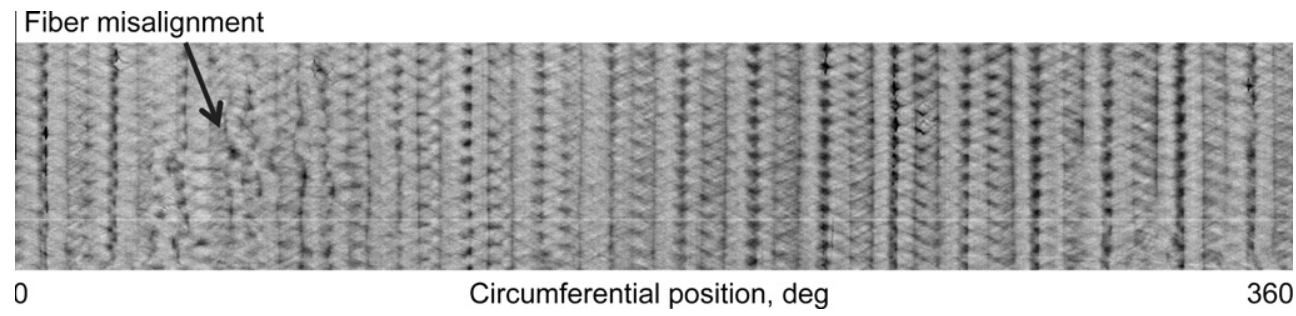

Fig. 13. Flattened circular cross section X-ray CT image showing fiber distortion. 


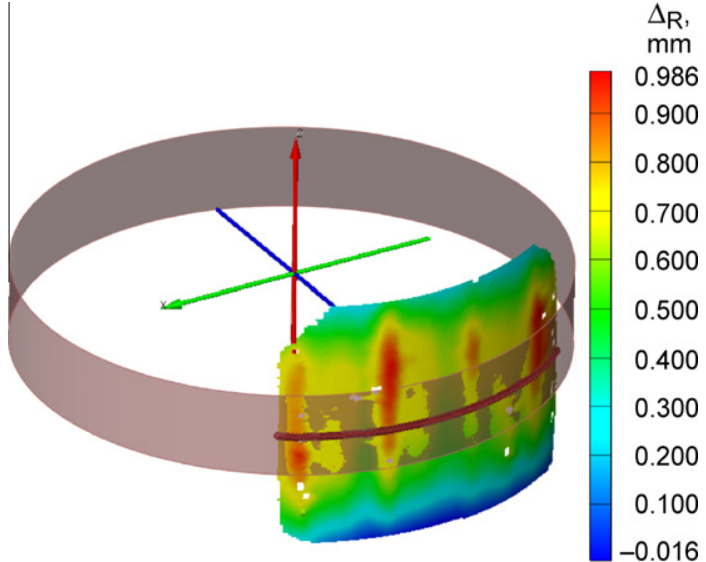

Fig. 15. An example of the cylindrical method for calculating strains. (For interpretation of the references to colour in this figure legend, the reader is referred to the web version of this article.)

Table 1

Tube burst strength compared to straight-sided and notch specimens for E862 matrix composite.

\begin{tabular}{|c|c|c|c|}
\hline & Straight-sided $^{\mathrm{a}}$ & Notched $^{\mathrm{a}}$ & Tube $^{\text {b }}$ \\
\hline \multicolumn{4}{|c|}{ Tensile Strength T700S/E862 (MPa) } \\
\hline Axial & $799.8(5)$ & $765.3(2)$ & \\
\hline Transverse & $461.9(5)$ & $813.6(2)$ & $627-1066$ \\
\hline
\end{tabular}

\section{Conclusions}

A notched coupon geometry was evaluated against the standard, ASTM D3039 based straight-sided tensile coupons for use with 2D triaxial braid composites. The notch specimen is simple to fabricate and forces a tensile failure for transverse specimens. Some of the limitations of this geometry are that it has a non-uniform gage region which results in a biaxial load state and it has stress concentration effects due to the notches. Despite these limitations, the notched coupon produced higher strength values compared to the straight-sided coupon. A limited set of partial pressurization tube tests produced a transverse tensile strength value that would more closely represent the actual tensile strength in a structure where failure is not influenced by free edges. The tube specimen removes the effects of free edges from the test but requires additional analysis and more complex and precise manufacturing methods to avoid defects compared to flat panel fabrication. The transverse strength measured by the notch specimens was much closer to the tubes than the straight-sided coupons. This indicates that the notched coupon should be used to provide an increased lower bound for the true transverse strength for these types of materials for the purpose of engineering composite structures. While the tubes serve as a validation test article for research purposes, these tests are not easily performed. The notched coupon provides a simple alternative for measuring transverse tensile strength while overcoming the edge initiated shear failure of the straight-sided coupon.

\section{Acknowledgement}

Partial funding for this work was provided through a NASA GSRP Grant \#NNX09AK92H.

\section{References}

[1] ASTM D3039. Standard test method for tensile properties of polymer matrix composites; 2000.

[2] Composite Materials Handbook. MIL-HDBK-17-3F. US DoD; 2002.

[3] Herakovich CT. Mechanics of fibrous composites. New York: John Wiley \& Sons, Inc.; 1998. p. 112

[4] Whitney JM, Daniel IM, Pipes RB. Experimental mechanics of fiber reinforced composite materials, revised ed. The society for experimental mechanics. Prentice Hall, Inc.; 1984. p. 56-66.

[5] Littell JD. The Experimental and analytical characterization of the macromechanical response of triaxial braided composite. Ph.D. dissertation. The University of Akron. Akron, Ohio; 2008.

[6] Littell JD et al. Characterization of damage in triaxial braided composites under tensile loading. J Aerospace Eng; July 2009.

[7] Littell JD et al. Full-field strain methods for investigating failure mechanisms in triaxial braided composites. NASA TM-2008-215197; 2008.

[8] Masters JE et al. Mechanical properties of triaxially braided composites: experimental and analytical results. NASA CR 189572; 1992.

[9] Roberts GD, Goldberg RK, Binienda WK, Arnold WA, Littell JD, Kohlman LW. Characterization of triaxial braided composite material properties for impact simulation. NASA TM 2009-215660; 2009.

[10] Ivanov DS, Baudry F, et al. Failure analysis of triaxial braided composite. Compos Sci Technol 2009;69:1372-80.

[11] Bowman CL, et al. Mechanical properties of triaxial braided carbon/epoxy composites. NASA TM-20030113144; 2003.

[12] Salem JA, Bail JL, Ghosn LJ, Roberts GD, Kohlman LW. Burst testing of triaxial braided composite tubes; in press.

[13] Gliesche $\mathrm{K}$ et al. Investigations of in-plane shear properties of \pm 45 -carbon/ epoxy composites using tensile testing and optical deformation analysis. Compos Sci Technol 2005;65:163-71.

[14] Dally JW, Riley WF. Experimental stress analysis. New York: McGraw-Hill; 1991. p. 47-8.

[15] Swanson SR, Smith LV. Comparison of the biaxial strength properties of braided and laminated carbon fiber composites. Composites Part B 1996;27B:71-7.

[16] Smith LV, Swanson SR. Strength design with 2-D triaxial braid textile composites. Compos Sci Technol 1996;56:359-65. 